\title{
Normalization and psychometric properties of career skills confidence inventory
}

\author{
Zahra Jafari $^{a^{*}}$, Amir Hossein Sadeghi Hasnijeha ${ }^{a}$ Reyhaneh Shojaee Jashvaghani ${ }^{b}$, Sedigheh \\ Shirvani ${ }^{\mathrm{b}}$, Mohammad Reza Iravanic ${ }^{\mathrm{c}}$ and Mohammad Reza Abedi ${ }^{\mathrm{d}}$
}

\begin{abstract}
${ }^{a}$ MS Student of Career Consulting, Counseling Department, Psychological and Education Science Faculty University of Isfahan, Isfahan, Iran ${ }^{b}$ MS Student of Counseling and Guidance, Counseling Department, Islamic Azad University of Khomeinishahr, Khomeinishahr Branch, Daneshjou Blvd, Isfahan, Iran

${ }^{c}$ Assistant Professor, Department of Social Work, Islamic Azad University Khomeinishahr Branch, Daneshjou Blvd, Isfahan, Iran ${ }^{d}$ Associate Professor, Counseling Department, Psychological and Education Science Faculty University of Isfahan, Isfahan, Iran

C H R O N I C L E

Article history:

Received December 2, 2012

Received in revised format

18 March 2013

Accepted 20 March 2013

Available online

March 252013

Keywords:

Betz questionnaire

Career counseling

Self-awareness

\section{A B S T R A C T}

This paper investigates normalization and psychometric properties of career skills confidence inventory. For this purpose, we use Betz's questionnaire [Betz, N. E., Harmon, L., \& Borgen, F. (1996). The relationships of self- efficacy for the Holland themes to gender, occupational group membership, and vocational interests. Journal of Counseling Psychology, 43, 90-98.], which consists of 60 questions in three groups of self-awareness, exploration and planning. The study distributes the questionnaire among 600 randomly selected students and analyzes the feedback using Pearson correlation ratios. The results indicate that there are some positive and meaningful correlations between three component and career counseling. There are also positive and meaningful relationships among three components of self-awareness, exploration and planning.
\end{abstract}

Exploration

Planning

\section{Introduction}

One of the primary concerns on any society is to build a good infrastructure so that people could find jobs much easier and faster. There are always some concerns among societies on how high school programs could be effective to create good background among students to help them learn more about their future careers. There are different tests to examine the level of students' preparation, which is called inventory. A concept inventory is a kind of test prepared to assess whether a student has an accurate working knowledge of a specific set of concepts or not and to make sure about interpretability, it is common to have multiple items, which address a single idea. The concept of inventories can be categorized as multiple-choice tests to ensure that they are scored in a reproducible manner, a feature that could also facilitate administration in large classes.

Corresponding author. Tel: +989132374434

E-mail: z.jafari366@gmail.com (Z. Jafari)

(C) 2013 Growing Science Ltd. All rights reserved. doi: 10.5267/j.msl.2013.03.021 
Betz et al. (1996) are believed to be pioneer for investigating the relationships of self- efficacy for the Holland themes to gender, occupational group membership, and vocational interests. They proposed a questionnaire for Skills Confidence Inventory (SCI), which have become popular among many scholars. Harmon et al. (1996) used SCI and General Confidence Theme (GCT) scores to differentiate between members of 21 occupational groups, appropriately. The GCT scales represented confidence in ability to perform tasks and complete courses in six areas. The occupational groups represented all six Holland kinds and encompassed both professional and nonprofessional fields. Betz and Hackett (1997) used this self-efficacy theory to the career development of women.

Betz et al. (1998) stated that gender could be considered as a moderator of the validity and interpretive utility of the SCI. Betz et al. (2003) described the development and psychometric evaluation of 17 scales measuring confidence or self-efficacy with respect to basic domains of vocational activity. Their confidence scales evaluate previously measured interest dimensions such as Writing, Public Speaking, etc. It also includes dimensions reflective of recent changes in the nature of work or the culture of the workplace, for instance, technology, creative production, etc. Borgen and Betz (2008) performed an empirical investigation on career self-efficacy and personality by looking the link between the career confidence inventory and the healthy personality inventory.

Lin and Betz (2009) studied some factors associated with the social self-efficacy of Chinese international students. Turner et al. (2010) performed a psychometric examination of an inventory of self- efficacy for the Holland themes using item response theory. Betz and Borgen (2010) studied the relationships of the Big Five personality domains and facets to dimensions of the healthy personality. In their survey, the psychometric properties of measures of self-efficacy for the six themes of Holland's theory were investigated using item response theory and all item and scale quality were compared across levels of the trait continuum. They reported that all the scales were highly reliable but differentiated better at some levels of the continuum than others.

Rim et al. (2011) performed some studies to add to knowledge of the structures and correlates of the two major maximization scales, the MS and the MTS, and to study the degree to which the underlying dimensions were associated with indices of mental health and well-being. They stated that there were not any noticeable differences in findings as a function of population, but they acknowledged in advance that their findings were limited to the samples they selected.

Turner et al. (2012) proposed a study on how to maximize inventory, which consisted of three separate scales including decision difficulty, alternative search, and satisficing. They explained that the items of the maximization inventory had much better psychometric properties when compared with the original Maximization Scale (Schwartz et al., 2002). In fact, Schwartz et al. (2011) argued that satisficing could be a better decision making strategy, which maximizes confidence in an acceptable outcome and frequently generates objectively better decision outcomes than maximizing under uncertainty. Turner's findings on positive relationships between satisficing and psychological well-being contributed to the growing body of evidence of the benefits of satisficing behaviors.

This paper investigates normalization and psychometric properties of career skills confidence inventory. The organization of this paper first presents details of the survey in section 2 while the findings are presented in section 3 and concluding remarks are given in the last to summarize the contribution of the paper.

\section{The proposed study}

According to career counseling theories (Betz et al., 1996), the more quickly people could be involved with job skills' components including self-awareness, exploration and planning, the more likely to find their suitable jobs and build their future. These components are important since when 
people are not familiar with their current circumstances, environment, rules and regulation, they may easily face with different challenges. The proposed study of this paper designs a questionnaire originally developed by Betz et al. (1996) and distributes it among 600 high school students who live city of Esfahan, Iran. The questionnaire was designed in Likert scale from "I don't believe at all" to "I do believe it".

The questionnaire had one general section, which was associated with personal information and three sub-section, including 11 questions on self-awareness, 18 questions were related to exploration and eleven questions were associated with planning. Cronbach alphas for self-awareness, exploration and planning are $0.72,0.83$ and 0.78 , respectively. The Cronbach alpha for the whole questionnaire has been calculated approximately as 0.8 , which validates the questionnaire. To verify the relationship among different components of the questionnaire, we use Pearson correlation test (Cohen, 1988) and the results are presented in the next section.

\section{The results}

In order to test the relationships of three components of questionnaire including self-awareness, exploration and planning with career counseling we have calculated Pearson correlation test and the results are summarized in Table 1 as follows,

\section{Table 1}

The results of Pearson correlation test between career counseling and three components of questionnaire

\begin{tabular}{lllll}
\hline Component & Self-awareness & Exploration & Planning & Total \\
\hline Pearson correlation & 0.366 & 0.302 & 0.366 & 0.261 \\
P-Value & 0.030 & 0.011 & 0.030 & 0.029 \\
\hline
\end{tabular}

As we can observe from the results of Table 1, all three components of the survey are statistically significant, which means there are meaningful and positive relationships between career counseling and self-awareness, exploration and planning when the level of significance is five percent.

Next, we have investigated the correlations among three components including self-awareness, exploration and planning and Table 2 shows details of the results of Pearson correlation ratios for these components.

Table 2

The results of Pearson correlation tests among three components of questionnaire

\begin{tabular}{lllll}
\hline Component & Statistics & Exploration & Planning & Total \\
\hline \multirow{2}{*}{ Self-awareness } & Pearson correlation & 0.61 & 0.47 & 0.76 \\
& P-Value & 0.000 & 0.000 & 0.000 \\
\hline \multirow{2}{*}{ Exploration } & Pearson correlation & & 0.62 & 0.92 \\
& P-Value & & 0.000 & 0.000 \\
\hline Planning & Pearson correlation & & & 0.83 \\
& P-Value & & 0.000 \\
\hline
\end{tabular}

The results of Table 2 demonstrate that there are positive and meaningful relationships among all three components of the questionnaire. The highest correlation exists between planning and exploration, 0.62, and the lowest correlation is between planning and self-awareness, which is 0.47. Therefore, we can conclude that three components of the survey have significantly influence on career development. 


\section{Conclusion}

In this paper, we have examined normalization and psychometric properties of career skills confidence inventory originally developed by Betz et al. (1996). The study has adopted their questionnaire consists of three parts including self-awareness, exploration and planning. The survey was performed among 600 students and the results confirmed that three components of selfawareness, exploration and planning had positive impact on career planning. The survey also revealed that there were positive correlations among three components of the survey.

\section{Acknowledgment}

The authors would like to thank the officials of high schools in city of Esfahan for their cooperation.

\section{References}

Betz, N. E., Harmon, L., \& Borgen, F. (1996). The relationships of self- efficacy for the Holland themes to gender, occupational group membership, and vocational interests. Journal of Counseling Psychology, 43, 90-98.

Betz, N. \& Hackett, G. (1997). Applications of self-efficacy theory to the career development of women. Journal of Career Assessment, 5, 383-402.

Betz, N., Borgen, F. Kaplan, A., \& Harmon, L. (1998). Gender as a moderator of the validity and interpretive utility of the Skills Confidence Inventory. Journal of Vocational Behavior, 53, 1-19.

Betz, N. E., Borgen, F. H., Rottinghaus, P., Paulsen, A., Halper, C. R., \& Harmon, L. W. (2003). The Expanded Skills Confidence Inventory: measuring basic dimensions of vocational activity. Journal of Vocational Behavior, 62(1), 76-100.

Betz, N. \& Borgen, F. (2010). Relationships of the Big Five personality domains and facets to dimensions of the healthy personality. Journal of Career Assessment, 18, 147-160.

Borgen, F. \& Betz, N. (2008). Career self-efficacy and personality: Linking the career confidence inventory and the healthy personality inventory. Journal of Career Assessment, 16, 22-43.

Cohen, J. (1988). Statistical power analysis for the behavioral sciences. New York: Academic Press.

Harmon, L. W., Borgen, F. H., Berreth, J. M., King, J. C., Schauer, D., \& Ward, C. C. (1996). The Skills Confidence Inventory: A measure of self-efficacy. Journal of Career Assessment, 4(4), 457477.

Lin, S-P. \& Betz, N. (2009). Factors related to the social self-efficacy of Chinese international students. The Counseling Psychologist, 37, 451-471.

Rim, H. B., Turner, B. M., Betz, N. E., \& Nygren, T. E. (2011). Studies of the dimensionality, correlates, and meaning of measures of the maximizing tendency. Judgment and Decision Making, 6(6), 565-579.

Schwartz, B. (2000). Self determination: The tyranny of freedom. American Psychologist, 55, 79-88.

Schwartz, B., Ben-Haim, Y., \& Dasco, C. (2011). What makes a good decision? Robust satisficing as a normative standard of rational decision making. Journal for the Theory of Social Behaviour, 41, 209-227.

Turner, B., Betz, N., Edwards, M. \& Borgen, F. (2010). Psychometric examination of an inventory of self- efficacy for the Holland themes using item response theory. Measurement and Evaluation in Counseling and Development, 43, 188-198.

Turner, B. M., Rim, H. B., Betz, N. E., \& Nygren, T. E. (2012). The maximization inventory. Judgment and Decision Making, 7, 48-60. 